\title{
Análise das interações entre sociedade e organização nas mídias sociais: um estudo da campanha "Papo de mulher para mulher" da loja Marisa
}

\author{
Anne Cristine Ferraz de Oliveira \\ Mestranda no Programa de Pós- \\ Graduação Stricto Sensu de \\ Comunicação Midiática da Faculdade \\ de Arquitetura, Artes e Comunicação \\ da Universidade Estadual Paulista Júlio \\ de Mesquita Filho (Faac-Unesp) de \\ Bauru. Graduada em Administração \\ pela Instituição Toledo de Ensino (ITE). \\ E-mail: annecris.ferraz@gmail.com
}

\section{Roseane Andrelo}

Doutora em Educação Escolar pela Unesp de Araraquara. Mestre em Comunicação Midiática pela Unesp de Bauru. Docente do Programa de PósGraduação em Comunicação Midiática da Faac-Unesp.

E-mail: roseane.andrelo@faac.unesp.br
Resumo: O artigo analisa a campanha "Papo de mulher para mulher" da loja Marisa e os comentários publicados nas mídias sociais, trabalhando na perspectiva do sistema de resposta social de José Luiz Braga. O objetivo principal do estudo é compreender como ocorre a construção do discurso de diversidade da Marisa a partir da análise das interações entre sociedade e organização, levantando pistas que levem à compreensão de como ocorre a comunicação organizacional voltada à diversidade e evidenciando as respostas sociais do público diante do discurso da loja no âmbito das mídias sociais. Constatou-se que o discurso de diversidade empregado pela organização não condiz com suas práticas e que grande parte dos leitores que comentaram na postagem tem posicionamento desfavorável à campanha, visto que não perceberam a representatividade de diferentes mulheres.

Palavras-chave: Mídias Sociais; Discurso da Diversidade; Comunicação Organizacional; Resposta Social.

Analysis of interactions between society and organization in social media: a study of the campaign "Papo de mulher para mulher" from Marisa store

Abstract: The article analyses the campaign "Papo de Mulher para Mulher" from Marisa store and the comments published in social media, working on the perspective of the social response system by José Luiz Braga. The main goal of the research is to understand how the construction of Marisa store's diversity discourse takes place considering the analysis of the interactions between society and organization, by raising clues that lead to an understanding of the organizational communication focused on diversity and evidencing the social responses of the audience regarding Marisa store's discourse in social media. We observed that the diversity discourse used by the organization is not consistent with its practices and that a large part of the readers who commented on the post has unfavorable position towards the campaign, since they did not perceive a representation of different women.

Keywords: Social Media; Diversity Discourse; Organizational Communication; Social Response. 


\section{Mídias sociais e comunicação organizacional}

As mídias sociais se configuraram nos últimos anos como um espaço de interação não somente entre usuários, mas também entre eles e grandes organizações, algo possibilitado pelas tecnologias de informação e comunicação (TIC). As empresas que divulgam suas ações nesses espaços têm a vantagem de poder alcançar muitas pessoas com bastante rapidez, tendo em vista o volume de usuários cadastrados na rede. Atualmente, um dos sites de rede social mais acessados mundialmente - e utilizado com esse propósito - é o Facebook, no qual existem aproximadamente 2 bilhões de usuários ativos (REUTERS, 2017).

Ellison e Boyd (2013 apud RECUERO; BASTOS; ZAGO, 2015) explicam que o site é uma plataforma de comunicação em rede na qual os participantes possuem perfis que articulam conexões - podendo ser vistas e cruzadas por outros - e que consomem, produzem e interagem com fluxos de conteúdo gerados por outros usuários. Assim, "se antes o foco estava nos perfis dos usuários, atualmente, esse foco recai sobre os fluxos de conteúdo" (RECUERO; BASTOS; ZAGO, 2015: 26).

As organizações que se utilizam das mídias sociais para realizar ações de comunicação organizacional possuem a chance de dialogar com seu público de forma mais próxima, além de possibilitar que os usuários da rede respondam diretamente às suas mensagens, criando um canal de comunicação de mão-dupla. Mas, mais do que isso, as mídias sociais permitem que a sociedade funcione também como geradora de conteúdo, ou seja, fonte produtora de sentidos em conjunto com as organizações, e não apenas como um polo de recepção.

Para estudar a comunicação organizacional nas mídias sociais é necessário fazer uma breve retrospectiva dessa área, que busca atingir o público de interesse das organizações, representado por alguns de seus stakeholders (clientes, fornecedores, comunidades nas proximidades da empresa, prestadores de serviços etc.).

Segundo Kunsch (2003), a comunicação organizacional deve ser estudada a partir de uma perspectiva integrada (comunicação organizacional integrada), que permite uma atuação sinérgica e engloba as seguintes subáreas: comunicação administrativa, comunicação interna, comunicação institucional e comunicação mercadológica. A autora afirma que a convergência de todas as atividades a partir de objetivos bem definidos é o que possibilitará ações de comunicação eficazes em níveis táticos e estratégicos.

A autora também salienta que a construção da credibilidade e a fixação de um posicionamento institucional coerente e duradouro dependem de "ações que devem ser sedimentadas na verossimilhança entre o discurso e a prática" (KUNSCH, 2003: 166).

Por esse motivo, caso a organização tenha um discurso incoerente com suas ações e esteja sujeita à exposição nas mídias sociais, qualquer fala pode repercutir diretamente na sua reputação. Da mesma forma que as mídias sociais permitem maior proximidade com o público e uma identificação positiva com os valores de uma empresa, elas podem ser igualmente destrutivas, considerando que é impossível controlar o que será comentado nas redes sociais a partir de determinada ação.

No caso da loja Marisa, busca-se compreender como o público constrói o discurso da diversidade em conjunto com a organização a partir da observação das interações entre sociedade e organização nas mídias sociais. Dessa forma, poderão ser levantadas pistas de como ocorre a apropriação do discurso organizacional de diversidade da Marisa pelos leitores e que tipo de respostas o público fornece a partir do momento em que os textos produzidos e difundidos pela organização passam a circular na sociedade por meio das mídias sociais.

\section{Discurso organizacional da diversidade nas mídias sociais}

Vivemos em um mundo em que a diversidade e a pluralidade de ideias e culturas fazem parte do dia a dia. No entanto, a luta pela inclusão de minorias (culturais, 
étnicas, de gênero, deficientes físicos) em todos os setores da sociedade é crescente, pois em vários lugares ainda existe forte resistência a essa diversificação.

Algumas organizações têm começado a notar a importância de implementar políticas de inclusão e gestão da diversidade. Quando mal administrada, a diversidade pode deixar a organização sujeita a perda de coesão dentro do grupo de funcionários e insatisfação dos membros majoritários na organização (JACKSON et al., 1991; TSUI et al., 1992; WHARTON; BARON, 1987 apud NKOMO; COX JUNIOR, 1999). Porém, organizações com um eficiente programa de gestão de diversidade - tanto cultural como de etnias, costumes, gênero, orientação sexual, religião etc. - tendem a ser mais inovadoras, demonstrando mais flexibilidade e criatividade na solução de problemas e nas tomadas de decisões (JACKSON et al., 1992; ANCONA; CALDWELL, 1992; BANTEL; JACKSON, 1989 apud NKOMO; COX JUNIOR, 1999). Alguns benefícios da diversidade cultural em organizações citados por Cox Junior (1994) são: retenção de talentos do mercado de trabalho dentro da organização; alcance e atendimento a segmentos de mercado diversificados; inovação, flexibilidade e melhoria na solução de problemas a partir da heterogeneização do corpo de funcionários.

No entanto, a questão da diversidade de gênero ainda é, em alguns casos, controversa, pois existem muitas empresas que, apesar de apresentarem mulheres em seu quadro de funcionários, lhes pagam salários menores quando exercem o mesmo cargo que homens. Outro problema surge quando, mesmo havendo mulheres a serviço de uma organização, nota-se a homogeneidade e padronização da aparência da mulher: em sua maioria, são mulheres brancas, magras, jovens e sofisticadas, características que reforçam o padrão hegemônico de beleza feminina. Mas, além da adoção de políticas inclusivas dentro da organização, também existe a preocupação em comunicar ao público externo como a empresa trabalha a questão da diversidade com estratégias de comunicação institucional e mercadológica.

Os discursos organizacionais empregados nessas estratégias representam os valores e crenças de uma organização e são recursos utilizados por ela para se tornar percebida por seus públicos. Segundo Charaudeau (2009), o discurso é construído dentro de determinada circunstância ou contexto social, que deve ser sempre considerado, e pode ser entendido como o resultado das características de quem fala, do que se fala e do modo como se fala com o objetivo de produzir sentidos. Ou seja, os discursos buscam sempre provocar algum efeito sobre o interlocutor.

É a partir dos discursos difundidos pela organização que são criadas as representações nas mentes do seu público e, consequentemente, sua imagem:

Numa organização, seja ela pública, privada, com ou sem fins lucrativos, podemos denominar "discurso organizacional" o conjunto dos "textos", ou seja, das manifestações expressivas de que essa organização se vale para tornar-se visível, percebida e apreendida pelos seus diversos públicos de interesse, internos e externos. (IASBECK, 2010: 408)

Por isso, é primordial que o discurso organizacional esteja alinhado com as práticas da organização, pois "discursos não coerentes ou distantes da realidade não geram coesão e não traduzem a cultura da organização, levando a dificuldades de identificação externa por clientes, comunidades e fornecedores" (IASBECK, 2010 apud CUNHA, 2015: 116).

Grandes empresas de vestuário, como a Marisa, têm buscado cada vez mais explorar o discurso da diversidade em suas campanhas publicitárias, principalmente na tentativa de incluir outros modelos que não sejam os padrões de pele branca/ clara, magreza e juventude, com a intenção de relacionar a imagem da organização a uma ideia de representatividade.

É dessa maneira que este estudo pretende investigar como se dá a exploração do discurso organizacional da diversidade a partir de uma campanha publicitária da Marisa divulgada nas mídias sociais - e, a partir da resposta que o público fornece, 
busca levantar pistas de como ele lê e se apropria desse conteúdo, construindo novos sentidos a partir do momento em que esse discurso passa a circular na sociedade. Dessa forma, a análise do diálogo entre sociedade e empresa possibilitará compreender se o público expressa concordância ou não com as falas da organização.

\section{Sistema de resposta social}

A internet possibilitou que instituições interagissem com a sociedade de forma distinta das mídias tradicionais, como jornal, rádio e televisão, as quais não permitem a reciprocidade e feedback do seu público. E isso se aplica também às estratégias de comunicação utilizadas pelas organizações, pois atualmente é pouco provável que não existam ações de comunicação organizacional nesse espaço. Por isso, mais do que nunca, nesse momento "as organizações são ativamente responsáveis tanto pela inter-relação com a mídia, com vistas a dar visibilidade aos seus princípios, como pela autogerência de sua representação, através de estratégias de comunicação organizacional" (KEGLER; BARICHELLO, 2007: 12).

Isso significa que, ao estarem presentes na internet e nas mídias sociais, as empresas estão sujeitas a interações com os destinatários-que podem ser positivas ou negativas, visto que a sociedade pode se apropriar dos discursos emitidos por essas organizações. Dessa forma, essas interações e apropriações podem contribuir para a construção da representação da empresa nos diferentes campos da sociedade contemporânea, tendo em vista que os destinatários são atuantes na qualidade da comunicação (KEGLER; BARICHELLO, 2007). Por isso, vale lembrar que uma ação ou fala da organização nesses espaços pode repercutir de forma inesperada, causando reações a favor ou contra os discursos produzidos e resultando em impactos na sua imagem.

Isso pode ser observado, por exemplo, quando uma empresa presente numa rede social tem problemas com produtos ou serviços prestados e seus clientes disparam comentários negativos, como reclamações e críticas, no perfil da organização. As redes sociais permitem que o público de uma organização elogie ou critique suas ações, de maneira que qualquer pessoa com acesso à internet e ao perfil da companhia possa visualizar os comentários - sendo eles positivos ou negativos. $\mathrm{Da}$ mesma forma, pode ocorrer também de uma campanha institucional ou publicitária ser exibida com uma intenção e ter retorno completamente diferente do esperado quando divulgada nas redes sociais.

A partir disso, traça-se um paralelo com o conceito de sistema de resposta social, ou sistema de interações sociais sobre a mídia, que compreende "atividades de resposta produtiva e direcionadora da sociedade em interação com os produtos midiáticos" (BRAGA, 2006: 22, grifo do autor). Segundo o autor, essas interações, em geral, resultam em respostas diferidas e difusas. Diferentemente do dualismo existente entre mídia e sociedade, em que a mídia é o sistema de produção, gerador de mensagens, e a sociedade é o sistema de recepção, meramente "recebedor", esse terceiro sistema representa uma sociedade que "age e produz não só com os meios de comunicação, ao desenvolvê-los e atribuir-lhes objetivos e processos, mas sobre os seus produtos, redirecionando-os e atribuindo-lhes sentido social" (BRAGA, 2006: 22). O autor chama atenção para a distinção do objeto a ser estudado, que trata da circulação de ideias, reações e respostas por meio das interações midiatizadas:

O sistema de interação social sobre a mídia (seus processos e produtos) é um sistema de circulação diferida e difusa. Os sentidos midiaticamente produzidos chegam à sociedade e passam a circular nesta, entre pessoas, grupos e instituições, impregnando e parcialmente direcionando a cultura. (BRAGA, 2006: 27, grifo do autor)

A definição trazida por Braga (2006) pode ser aplicada no âmbito das mídias sociais e no contexto das organizações, tendo em vista que a partir de observações desses atores - sociedade e organizações - pode-se empregar o sistema de 
resposta social para compreender como se dão seus movimentos daquela diante do discurso produzido e disseminado pelas organizações. Para o autor, o fenômeno de midiatização coloca a mídia hoje como parte estruturante da sociedade, e não apenas como produtora de mensagens. Kegler e Barichello (2007: 8) ainda explicam que o processo de midiatização trata a mídia como "principal responsável pelos processos de interações sociais, bem como da construção social em si".

Assim, as práticas sociais são perpassadas pela mídia: isso significa que as mensagens veiculadas pela mídia circulam pela sociedade, e após essa circulação a sociedade se apropria dos discursos midiáticos, ressignificando-os - e, também por meio da mídia, esboça reações e respostas, como comentários, sejam eles críticos ou positivos, sobre os discursos das organizações.

De acordo com Oliveira, Henriques e Paula (2012: 173), as organizações têm se utilizado de estratégias provenientes do campo midiático para estreitar seu relacionamento com o público, visto que "como atores sociais coletivos, as organizações precisam também legitimar sua atuação junto aos demais atores, o que fazem, essencialmente, através de suas competências discursivas". Os autores também ressaltam que as estratégias midiatizadas utilizadas pelas organizações fazem parte de um campo que merece atenção dos pesquisadores que buscam compreender a sociedade contemporânea, visto que:

Trata-se da esfera onde os atores sociais constroem discursos e buscam, através deles, legitimar sua atuação e onde esses mesmos discursos ganham repercussão social, sendo permanentemente apreendidos, reelaborados e postos em circulação. O fenômeno da midiatização se configura, assim, como o processo interacional estruturante da sociedade nos dias de hoje. Acredita-se que o viés mais promissor de análise da midiatização no campo da comunicação social é entendê-la não apenas sob a ótica das intencionalidades dos emissores e receptores, mas também dos mecanismos de resposta social que o discurso midiático produz. (OLIVEIRA; HENRIQUES; PAULA, 2012: 171)

É sob essa perspectiva que será estudada a campanha realizada pela loja Marisa, em que é pertinente compreender como ocorre a circulação do conteúdo produzido pela organização nas mídias sociais e as respostas da sociedade, manifestadas por intermédio de comentários críticos ou positivos frente ao discurso da diversidade difundido pela empresa.

\section{Interações entre o perfil Vou de Marisa e seu público nas mídias sociais}

Para desenvolver este estudo, foi selecionado um comercial da campanha publicitária "Papo de mulher para mulher" da Marisa, que foi veiculado na televisão em março de 2016. O comercial também foi publicado na página oficial Vou de Marisa no Facebook, em 3 de março de 2016, alguns dias antes do Dia Internacional da Mulher (8 de março). A empresa buscou explorar a temática da diversidade dos corpos femininos, tendo em vista que, principalmente a partir de 2010, tem-se observado um movimento crescente de mulheres que buscam representação na sociedade -negras, LGBT, de diferentes classes sociais, obesas, que até décadas atrás se encontravam à margem da sociedade e não eram aceitas, sendo alvo de discriminação.

O objetivo do estudo foi identificar quais eram as intenções e falas da organização ao veicular essa campanha e, em conjunto - aplicando a análise de conteúdo, a fim de categorizar e classificar os comentários, e trabalhando com o conceito de sistema de resposta social -, buscar compreender as reações do público no Facebook. Pode-se observar nas mídias sociais a repercussão dos conteúdos produzidos pela organização, visto que essa ferramenta possibilita a interação direta entre emissor e receptor; por isso, o Facebook será considerado aqui como um dispositivo de resposta social.

No comercial selecionado, três mulheres observavam e elogiavam a outra modelo enquanto ela experimentava diferentes lingeries. Percebe-se, pela escolha das atrizes, 
e por algumas das respostas selecionadas nos comentários do Facebook, que o objetivo da loja foi demonstrar a diversidade, representando algumas das diferentes etnias existentes no Brasil, além de dar visibilidade a mulheres com diferentes tipos de corpos e alturas, e não apenas mulheres brancas, altas e magras - que são geralmente representadas nos comerciais de moda. Como exemplo, pode-se observar um dos comentários publicados pela página oficial da loja, denominada Vou de Marisa, em 8 de março de 2016:

${ }^{1}$ Cf. PAPO..., 2016.
Silvia, nossa intenção é mostrar que todas as mulheres independente do corpo podem usar a lingerie que se sintam bem para usar, sendo magra ou gorda pois todas nós em algum momento, temos inseguranças que precisam ser vencidas pela nossa autoestima. Muitas mulheres são reféns dos padrões de beleza. Mesmo quem está dentro deles, é afetado, porque padrões e estereótipos tentam limitar as pessoas. Acreditamos que toda pessoa tem que ter liberdade de ser quem é, do jeito que quiser. Feliz dia da mulher! ${ }^{1}$

A análise de conteúdo permite realizar a inferência dos aspectos latentes de uma mensagem, ou seja, o analista pode inferir (deduzir de maneira lógica) conhecimentos e intenções sobre o emissor ou destinatário da comunicação a partir de seus enunciados (BARDIN, 2011).

Com base na fundamentação teórica e a partir da análise de conteúdo conduzida, foram criadas três categorias para classificar os 76 comentários publicados na página oficial no Facebook da Marisa no vídeo do comercial em questão. Ao todo, a publicação somou 131 mil visualizações, 178 compartilhamentos e aproximadamente 1.400 curtidas. As categorias criadas são: 1) posicionamento favorável ao comercial: se enquadram leitores que perceberam a iniciativa da Marisa de forma positiva, elogiando a marca por propor modelos diferentes das tradicionalmente contratadas para representar as mulheres em ações de publicidade; 2) posicionamento contra o comercial: leitores que criticaram a escolha das modelos, por acreditarem que elas não representam a diversidade das mulheres brasileiras; e 3) neutros: leitores que não criticaram nem apoiaram a ação da organização, comentários curtos demais ou em que não ficou claro o posicionamento, ou ainda leitores que comentaram sobre outros assuntos referentes à organização, como pedidos ou qualidade dos produtos.

Do total de comentários, 17 são respostas da página oficial Vou de Marisa a comentários de leitores e 59 são de seguidores da página. Portanto, os 59 comentários dos leitores ficaram distribuídos na seguinte proporção:

\begin{tabular}{|l|l|l|}
\hline Categorias & Quantidade & Percentual \\
\hline Posicionamento favorável & 5 & $8,4 \%$ \\
\hline Posicionamento desfavorável & 20 & $33,9 \%$ \\
\hline Neutros & 34 & $57,7 \%$ \\
\hline
\end{tabular}

Quadro 1: Posicionamento dos leitores em relação ao comercial

Fonte: Elaborado pelas autoras

Entre os comentários favoráveis e desfavoráveis ao discurso adotado pela loja, os principais argumentos encontrados são:

\begin{tabular}{|l|l|}
\hline Posicionamento favorável & Posicionamento desfavorável \\
\hline $\begin{array}{l}\text { As modelos representam a diversidade } \\
\text { de corpos (gordas e magras) }\end{array}$ & $\begin{array}{l}\text { As modelos não representam a } \\
\text { diversidade de etnias }\end{array}$ \\
\hline Avaliação positiva da campanha da loja & $\begin{array}{l}\text { Não existe numeração de peças para } \\
\text { mulheres gordas }\end{array}$ \\
\hline & $\begin{array}{l}\text { As modelos não representam a } \\
\text { diversidade de corpos (gordas e } \\
\text { magras) }\end{array}$ \\
\hline
\end{tabular}

Quadro 2: Argumentos mais frequentes apresentados por leitores

Fonte: Elaborado pelas autoras 
${ }^{2}$ Cf. PAPO..., 2016.

${ }^{3}$ Cf. PAPO..., 2016.
Em um dos comentários em que há posicionamento contra o discurso da Marisa, a leitora Sarah Carolina demonstrou sua indignação com a marca referindo-se à escolha de apenas uma mulher negra para representar a diversidade de etnias e à falta de representação das demais etnias, bem como de deficientes:

Eu tô cansada de comerciais com mulheres brancas em sua maioria e uma única negra. Parece que "vamos colocar UMA alí, pra n [não] acusarem a gente de racismo ou afirmarem q [que] n [não] estamos sendo representativos". Vc [você] pega um grupo de mulheres no Brasil e existem tantas formas e cores que esses comerciais passam a ser irreais. Vcs [vocês] colocam mulheres de vários tipos de corpo, mas esquecem como representar índios, negros, descendentes de japoneses, deficientes físicos e semelhantes. tbm [também] é importante!!!!!!?

Ao analisar os próximos comentários, constatou-se que o discurso de diversidade empregado pela loja foi apreendido e compreendido de forma diversa da pretendida pela organização pela leitora Mayara Barreto. E, ao relatar seu ponto de vista trazendo também a percepção de uma amiga para as mídias sociais, a seguidora fez com que o discurso da organização passasse a circular na sociedade também por outro meio que não a mídia.

Dessa forma, a utilização do conceito de sistema de resposta social no âmbito da comunicação organizacional é adequada para a situação, conforme a análise que segue:

Marisa, se é pra falar de aceitação do corpo, vamos botar mulher gorda? Que essas dai podem ate sofrer um pouco da pressão sob a estética feminina, mas nem se compara com uma mulher gorda... aliás o preconceito é tanto que não tem gorda nesse comercial que fala sobre aceitação $\neg$ ( tipo só se aceite até o 40/42?!!!)

Marisa... tomei a liberdade de conversar com meninas gordas... e elas não estão se sentindo representadas... seria interessante ouvi-las verdadeiramente ${ }^{3}$

Nesse momento, nota-se que o discurso midiático produzido pela organização começa a circular pela sociedade, perpassando outras instâncias que não a mídia, e se instaura nas relações sociais, voltando em forma de resposta na própria mídia social. A leitora Mayara Barreto levou o conteúdo do comercial ao conhecimento de uma amiga, se apropriando dos sentidos produzidos e relatando o que foi percebido por elas - e o resultado não foi necessariamente coerente com o discurso da diversidade e com as intenções que a Marisa pretendia propagar, tendo em vista que a amiga da leitora não se sentiu representada no comercial da organização.

Outro comentário relevante foi o da leitora Jéssica Feliciano:

Só não compro nada na marisa porque simplesmente não existe sutian tamanho 56 ou 54b. Isso irrita demais uma marca deste calibre não ter esta numeração até o 54 é dificil de achar..... sacanagem com quem tem busto grande. ${ }^{4}$

Pode-se perceber, nesse caso, a incoerência entre o discurso da organização e as práticas adotadas por ela, pois na campanha selecionada a empresa busca representar a diversidade de mulheres, no entanto, a cliente e seguidora da página relata que não encontra numeração de peças acima do 54 .

Entre os comentários favoráveis ao posicionamento da loja no comercial em questão, destacaram-se os que seguem: 
${ }^{5}$ Cf. PAPO..., 2016. amei esse novo comercial da Marisa com mulheres mais gostosas ou seja mais fofinhas kkkkkklkk

agr [agora] sim... Modelo de verdade. Pq [porque] o padrão pra corpo ideal é o corpo q [que] cada um tem. Não sou obrigada a ser magrela, já bastou a adolescência. ${ }^{5}$

Dessa forma, nota-se que as interações resultaram em uma pluralidade de discursos, que ora reafirmam as falas da organização, ora as criticam. Porém, ao expressar as opiniões pessoais, nota-se, principalmente nos comentários críticos à campanha, uma maior argumentação e enfrentamento dos leitores que levaram seu posicionamento a público, com a formulação de explicações, demonstrações ou pressões sobre a organização. Os comentários desfavoráveis também geraram mais debates entre os leitores do que os comentários positivos. O comentário da leitora Mayara Barreto gerou ainda mais discussões entre outras seguidoras da página, como pode ser observado na Figura 1:

Mayara Barreto Marisa, se é pra falar de aceitação do corpo, vamos botar mulher gorda? Que essas dai podem ate sofrer um pouco da pressao sob a estética feminina, mas nem se compara com uma mulher gorda. aliás o preconceito é tanto que nao tem gorda nesse comercial que fala sobrr aceitaçao $\neg$ ( tipo so se aceite até o $40 / 42 ? ! ! !)$

(1) 7 . 4 de março de 2016 às 08:56

III

Vou de Marisa $\bigcirc$ Mayara, a nossa coleção é para todas as mulheres, do 36 ao 54 . Nós celebramos a diversidade das brasileiras e sempre tentamos representá-las em nossas campanhas. Acreditamos que toda pessoa tem que ter liberdade de ser quem é, do jeito que quiser. Também temos campanhas exclusivas para Plus Size. 4 de março de 2016 às 11:28

Mayara Barreto Marisa... tomei a liberdade de conversar com meninas gordas... e elas nao estao se

2 sentido representadas... seria interessante ouvi-las verdadeiramente (1) 3 - 4 de março de 2016 às $12: 27$

Fernanda Bastos Falei a mesma coisa no outro comercial, e eles continuam com este discurso... AFF De que adianta atender às gordas só no provador, às escondidas?! Bota a cara pra bater e faz um comercial que represente de vdd as gordas! O 3.4 de março de 2016 às $12: 41$

1. Rita Mara Silva Aquela moça tem o corpo perfeito, de gorda ela não tem nada. Que palhaçada! Ah se toda mulher tivesse um corpo daquele! $\mathrm{O}$ tiro saiu pela culatra. Isso ai ta dizendo $q$ uma mulher linda $e$ perfeita é gorda. Imagine como as q tem uma gordurinhas a mais se sentem ao verem um comercial tão escroto desse. Me engana q eu gosto! (1) 3.6 de março de 2016 às $16: 39$

Figura 1: Interações nos comentários da página do Facebook Vou de Marisa Fonte: PAPO..., 2016.

Notou-se que, enquanto os comentários positivos foram mais abstratos, apenas apoiando a campanha de forma indefinida, os comentários negativos colaboraram para incentivar a organização a repensar suas atitudes, cobrando ações concretas da empresa para que ela represente, tanto na mídia como fora dela, a diversidade das mulheres.

\section{Considerações finais}

A partir da análise de conteúdo conduzida foi possível observar que as respostas sociais dos leitores são, de fato, de ordem diferida e difusa, visto que, ao circularem pela sociedade, produzem novos sentidos que podem ser diversos dos empregados pela organização nas mídias sociais. Dessa forma, durante a pesquisa, constatou-se que não necessariamente as respostas dos atores sociais correspondem apenas à afirmação ou negação do discurso da empresa, podendo gerar falas que vão além do tema da diversidade.

Grande parte dos comentários (57,7\%) envolvia respostas desconexas que não dialogavam diretamente com o tema da diversidade empregado no discurso da Marisa. Apesar disso, a maioria das respostas que buscava interação com a organização a partir do discurso da diversidade $(33,9 \%)$ foi contrária ao posicionamento da loja no comercial analisado, apontando diversas falhas na coerência entre discurso e práticas da organização. Do total de comentários, apenas $5(8,4 \%)$ foram favoráveis ao discurso da loja no comercial. 
Concluiu-se que, ao publicar o comercial nas redes sociais, a loja Marisa ficou suscetível a comentários e críticas da sociedade, e muitos leitores não encararam o discurso da organização de forma positiva. A temática da diversidade explorada pela empresa não foi bem aceita pelo público, por fatores variados, como o fato de os seguidores não se sentirem representados na campanha ou de a empresa adotar um discurso que não condiz com suas práticas. Segundo alguns leitores, a organização não foi inclusiva, pois não disponibiliza tamanhos de roupas para pessoas com sobrepeso, e ainda não retratou em sua campanha uma maior diversidade de etnias e pessoas com deficiência. Ademais, pode-se perceber na análise que os comentários críticos geraram maior interação entre as leitoras, que cobraram atitudes mais práticas da organização, como o desenvolvimento de campanhas com maior diversidade de mulheres e a inclusão de peças em tamanhos maiores em sua grade de numerações.

Portanto, o conceito de sistema de resposta social ou sistema de interações sociais sobre a mídia apresentado por Braga (2006) pode ser observado na prática no momento em que a sociedade se manifesta nas mídias sociais, ressignificando os discursos da organização e se apropriando das suas falas. Essas conversações demonstram que a mídia está presente nas relações sociais e que os discursos midiáticos circulam na sociedade, perpassando a própria mídia e sempre criando novos sentidos à medida que ocorre essa circulação.

Também ficou clara a importância do alinhamento entre discurso e ações da organização, principalmente em um momento em que a sociedade pode reagir e gerar conteúdo a partir das falas da organização. A construção do discurso da diversidade não depende mais apenas da organização, pois ao direcionarmos o olhar para o campo da recepção e seus posicionamentos, observa-se a produção de sentidos a partir das interações entre sociedade e organização nas mídias sociais, por meio do fenômeno da midiatização.

\section{Referências}

ANCONA, D. G; CALDWELL, D. F. Demography and design: predictors of new product team performance. Organization Science, v. 3, n. 3, p. 321-341, 1992.

BARDIN, L. Análise de conteúdo. 3. reimp. Lisboa: Edições 70, 2011.

BRAGA, J. L. A sociedade enfrenta sua mídia: dispositivos sociais de crítica midiática. São Paulo: Paulus, 2006.

CHARAUDEAU, P. Discurso das mídias. São Paulo: Contexto, 2009.

COX JUNIOR, T. Cultural diversity in organizations: theory, research and practice. San Francisco: Berrett-Koehler, 1994.

CUNHA, C. D. Luiz Carlos Assis lasbeck: a comunicação como construção de vínculos e seu potencial na administração das identidades das organizações. In: OLIVEIRA, I. L.; PENNINI, A.; MOURÃO, I. (Orgs.). Compreendendo um campo de conhecimento: reflexões epistemológicas sobre a comunicação organizacional a partir de autores brasileiros. Curitiba: CRV, 2015.

IASBECK, L. C. A. Discurso na gestão da comunicação. In: MELO, J. M. (Org.). Enciclopédia Intercom de comunicação. São Paulo: Sociedade Brasileira de Estudos Interdisciplinares da Comunicação, 2010. v. 1. p. 408-409.

JACKSON, S. E.; BRETT, J. F.; SESSA, V. I.; COOPER, D. M.; JULIN, J. A.; PEYRONNIN, K. Some differences make a difference: individual dissimilarity and group homogeneity as correlates of recruitment, promotions, and turnover. Journal of Applied Psychology, v. 76, n. 5, p. 675-688, 1991. Disponível em: <https://bit.ly/2rbDurL>. Acesso em: 17 abr. 2018. 
JACKSON, S. E. et al. Diversity in the workplace: human resource initiatives. Nova York: Guilford Press, 1992. Disponível em: <https://bit.ly/2r90xUW>. Acesso em 17 abr. 2018.

KEGLER, J. Q. S.; BARICHELLO, E. M. M. R. As organizações sociais no espaço midiatizado: os suportes digitais como meios e estratégias de representação organizacional. Sociais e Humanas, Santa Maria, v. 20, n. 2, p. 99-107, 2007.

KUNSCH, M. M. K. Planejamento de relações públicas na comunicação integrada. 5. ed. São Paulo: Summus, 2003.

NKOMO, S. M.; COX JUNIOR, T. Diversidade e identidade nas organizações. In: CALDAS, M. P.; FACHIN, R.; FISCHER, T. (Orgs.). Handbook de estudos organizacionais: modelos de análise e novas questões em estudos organizacionais. São Paulo: Atlas, 1999. v. 1. p. 332-358.

OLIVEIRA, I. L.; HENRIQUES, M. S.; PAULA, M. A. A sociedade enfrenta suas organizações?: interação entre organizações e sociedade nas mídias sociais articulada pelo discurso da sustentabilidade. Esferas, Brasília, n. 1, p. 169-178, 2012. Disponível em: <https://bit.ly/2GzG59n>. Acesso em: 31 maio 2017.

PAPO de mulher para mulher. Vou de Marisa, [S. I.], 2016. Facebook. Disponível em: <https://www.facebook.com/voudemarisa/videos/965543923528917/>. Acesso em: 1 dez. 2017.

RECUERO, R.; BASTOS, M.; ZAGO, G. Análise de redes para mídia social. Porto Alegre: Sulina, 2015.

REUTERS. Facebook chega a 1,94 bilhão de usuários em todo o mundo no 10 trimestre de 2017. G1, [S. I.], 4 maio 2017. Disponível em: <https://glo.bo/2qvwck5>. Acesso em: 23 maio 2017.

TSUI, A. S., EGAN, T. D.; O'REILLY, C. Being different: relational demography and organizational attachment. Administrative Science Quarterly, v. 37, n. 4, p. 549579, 1992. 